\title{
Improving the Technology of Bitter Tinctures
}

\author{
Iryna Sokolovska, Roman Zherebetskyi, Oksana Orobchuk, Roman Subtelnyi
}

Department, of Technology of Organic Products, Lviv Polytechnic National University, UKRAINE, Lviv, S. Bandery street 12, E-mail: oksana.m.orobchuk@1pnu.ua, iryna.sokolovska.mxr.2020@lpnu.ua

Abstract - Improving the technology of bitter tinctures have been investigated. The new recipe for the drink have been proposed. In order to improve the traditional scheme of extraction of aromatic raw materials, the use of the extractor with a rotary pulsation pump have been proposed.

Keywords - extraction, bitter tincture, rotary-pulsation extractor, ethanol, technology, juniper, thorns, echinacea.

\section{Introduction}

One of the main stages in the manufacture of tinctures is extraction. Extraction is the process of extracting substances from raw materials using an extractant, the process is based on the difference in the coefficients of distribution of extractives between the phases of liquid and solid [1]

Good solvent are methanol, ethanol, acetone, water and ethyl acetate. But when choosing an extractant for the production of bitter tincture, it must meet the requirements: the extractant must not mix with the extraction raw material, well dissolve the target compounds and do not dissolve impurities, no toxicity to humans. Given all the above requirements, ethanol is used as an extractant, because it is a universal solvent, due to its molecular structure is able to dissolve polar hydrophilic and non-polar hydrophobic compounds [2].

A complex extraction process is a combination of a number of processes: wetting, swelling, dissolution, chemical interaction, adsorption, desorption, diffusion, dialysis. There are three main stages:

- impregnation of vegetable raw materials with extractant is carried out due to capillary forces;

- swelling and dissolution of plant cell components;

- mass transfer is the process of transition of a substance from one phase to another [3].

The extraction process can be accelerated by increasing the contact area of the phases, the porosity of the extractive layer, creating the optimal ratio of extractant and extractive raw materials, increasing the temperature, ensuring the dynamic movement of the extractant.

In the process of making extracts for tinctures usually use the method of classical maceration. The essence of which is that the extraction raw material is poured into a container, filled with extractant and infused for 5 - 10 days. Obtaining the extract by this method requires a significant amount of time and the resulting extract is low in concentration. That is why other extraction methods have started to be used in the industry, namely: extraction with the use of ball mills, extraction with the use of rotary pulsation devices, extraction with liquefied gases, filtration extraction, etc. [4].

The use of a rotary pulsation extractor and a new formulation of the drink is proposed in order to improve the process of making bitter tincture.

The search and characterization of new methods of improving the process of making bitter tinctures, development of new recipes for bitter tinctures using local raw materials was the aim of research. 


\section{Results and Discussion}

Bitter tinctures are an alcoholic beverage obtained by extracting spicy-aromatic raw materials with alcohol or water. A significant number of modern brands of bitter tinctures have been created as medicines. But due to their spicy bitter-sweet and harmonious taste, they began to be often used in cocktails and as aperitifs [5].

After analyzing the existing recipes for bitter tinctures, a new recipe for the drink is proposed, which will include components of local origin, namely juniper, thorns, echinacea, apple and pear leaves. This raw material has not only good spicy-aromatic properties, but also contains a significant number of useful elements, especially ascorbic acid.

In order to improve the traditional scheme of extraction of spicy-aromatic raw materials, it was decided to use an extractor with a rotary pulsation pump, which will ensure the constant movement of the extractant through the extractive layer. Aromatic raw materials are loaded into the extractor through the upper hatch, then the extractant (ethanol) is fed. The extraction process is carried out by continuously pumping the extractant from the bottom of the extractor to the top. Thus the maximum degree of release of aromatic substances from vegetable raw materials in a short time is reached.

This method allows you to get the finished extract in two days, not 5 - 10. Accelerated extraction allows you to more efficiently use the resources of the entire production equipment.

\section{Conclusion}

An improved scheme for the production of bitter tinctures is proposed and the cost coefficients per 1 dal of drink are calculated. Selected innovations allow to reduce the extraction time and, in turn, the production time of the finished drink from 250 to 175 days. Due to the intensification of all processes, the cost of wages to employees is reduced and it is possible for the company to produce a wider range of products. Local raw materials are cheaper and more affordable, which has a positive effect on the cost of the finished drink. Selected innovations reduce the extraction time and, in turn, the time off.

\section{References}

[1] Diachok, V.V. 2010. Scientifically are theoretical bases of extracting from a medical vegetal raw material. Thesis for a doctor of technical sciences degre. Kyiv, $41 \mathrm{p}$.

[2] Zubrick, J.W. 2014. The organic chem lab survival manual: a student's guide to techniques. Hoboken: John Wiley \& Sons, 346 p. ISBN 9781118083390.

[3] Kazarynov, M.O., Kabachna, A.V. 2015. Praktykum z promyslovoi tekhnolohii likarskykh zasobiv. NFaU, 374 p.

[4] Handa, S.S., Khanuja, S.P.S., Longo, G., Rakesh, D.D. 2008. Extraction Technologies for Medicinal and Aromatic Plants. International centre for science and hightechnology. Trieste, $266 \mathrm{p}$.

[1] Ramalakshmi, K., Raghavan, B. 1999. Caffeine in Coffee: Its Removal. Why and How? Critical Reviews in Food Science and Nutrition, 39 (5), 441-456. doi:10.1080/10408699991279231. ISSN 1040-8398. 